\title{
A Cost Effective Fermentative Production of Glutathione by Saccharomyces cerevisiae with Cane Molasses and Glycerol
}

\author{
Andréia Anschau ${ }^{1 *}$, Lucielen Oliveira dos $\operatorname{Santos}^{2}$ and Ranulfo Monte Alegre ${ }^{1}$ \\ ${ }^{I}$ Departamento de Engenharia de Alimentos; Faculdade de Engenharia de Alimentos; Universidade Estadual de \\ Campinas; Campinas - SP - Brasil. ${ }^{2}$ Escola de Química e Alimentos ; Universidade Federal do Rio Grande; Rio \\ Grande - RS - Brasil
}

\begin{abstract}
This work aimed to evaluate the effect of sugar cane molasses and glycerol on glutathione (GSH) fermentation by Saccharomyces cerevisiae ATCC 7754 in flask culture using response surface methodology. Under optimized conditions ( $80 \mathrm{~g} / \mathrm{L}$ of molasses and $60 \mathrm{~g} / \mathrm{L}$ of glycerol), the highest GSH and biomass concentration achieved were $119.6 \mathrm{mg} / \mathrm{L}$ and $25.3 \mathrm{~g} / \mathrm{L}$, respectively. Further studies done in 5 L bioreactor resulted $241.3 \mathrm{mg} / \mathrm{L} \mathrm{GSH}$ after $96 \mathrm{~h}$ in batch fermentation without amino acids addition and the concentration of biomass was $12.1 \mathrm{~g} / \mathrm{L}$. In batch fermentation with the addition of the three amino acids (4 mM cysteine, glycine and glutamic acid at 32 h), biomass reached to $25 \mathrm{~g} / \mathrm{L}$ and $\mathrm{GSH}, 236.1 \mathrm{mg} / \mathrm{L}$ at $96 \mathrm{~h}$ of fermentation. The strategy of precursor amino acids addition is a key aspect in increasing the synthesis of GSH.
\end{abstract}

Key words: Glutathione, Fermentation, Fed Batch Culture, Amino Acids, Response Surface Methodology

\section{INTRODUCTION}

Glutathione (GSH) is a biologically active tripeptide consisting of L-glutamate, L-cysteine and glycine (L- $\gamma$-glutamyl-L-cysteinylglycine) (Zhang et al. 2007). It is the mainly abundant nonprotein thiol compound present in living organisms, from prokaryotes to eukaryotes (Rollini and Manzoni 2006). GSH is considered to be one of the most important self-generated defense molecules (Maris et al. 2000). In humans, GSH deficiency can be associated with many diseases, such as liver cirrhosis, pulmonary diseases, gastrointestinal and pancreatic inflammations, diabetes, neurodegenerative diseases, and aging (Navarro et al. 1999). GSH is widely used as a drug and has great potential to be used in food additives and in the cosmetic preparations, if the price can be decreased further
(Li et al. 2004). GSH can be produced by enzymatic methods and also by fermentation. In the latter method, the yeasts Saccharomyces cerevisiae and Candida utilis are used to produce GSH at industrial scale (Navarro et al. 1999). $S$. cerevisiae is a versatile and simple eukaryotic model organism. This facultative anaerobe is able to live on various carbon sources, including fermentable and non-fermentable substances (Magherini et al. 2009).

To produce GSH cost-effectively on an industrial scale by yeast fermentation, more economical carbon and nitrogen sources should be investigated. Molasses, the by-product of sugar manufacturing, is cheap and abundant material. The carbohydrates (glucose, sucrose, and fructose) present in molasses suggest that it could be an excellent carbon source. On the other hand, the additional nutrients, such as vitamins and

*Author for correspondence: andreiaanschau@ hotmail.com 
minerals, in molasses endow it with superior performance (Beshay and Moreira 2005). The use of renewable waste substrates is an environmentally-friendly choice that also contributes to the reduction of waste treatment costs and increases the economic value of byproducts. Glycerol is a versatile carbon and energy source with many possible applications in industrial fermentation (Silva et al. 2009). Glycerol is not only cheap and abundant, but its higher degree of reduction than sugars offers the opportunity to obtain reduced chemicals, such as succinate, ethanol, xylitol, propionate, hydrogen, etc. at higher yields than those obtained from the sugars (Dharmadi et al. 2006). In yeast fermentations due to the Crabtree effect, respiratory enzymes are inhibited and ethanol is formed when the substrate concentration is above a critical value, which results in a decrease in biomass productivity (De Deken 1966). This problem can be overcome by fed-batch fermentation in which essential nutrients can be fed incrementally to the bioreactor during the cultivation. In order to optimize the fermentation process to achieve a maximum biomass yield and a high biomass concentration, a suitable control strategy has to be developed (Wen et al. 2006).

GSH biosynthesis has close relationship with three constituent amino acids. Cysteine addition accompanied by glycine and glutamic acid can improve GSH production (Wen et al. 2005). However, cysteine addition would cause growth inhibition, while the introduction of glutamic acid and glycine can weaken the inhibition effect (Wang et al. 2007). The objective of this study was to develop an economic method for the GSH production using $S$. cerevisiae ATCC 7754 . The initial approach was to use molasses and glycerol as inexpensive carbon sources. A feedback control strategy and the effect of precursor amino acids addition were investigated.

\section{MATERIAL AND METHODS}

\section{Microorganism and Culture Media}

Saccharomyces cerevisiae ATCC 7754 was used throughout this study. Stock cultures were maintained at $4^{\circ} \mathrm{C}$ on Yeast Malt (YM) agar. The inoculum was carried out on rotary shaker, using Erlenmeyer flasks $(250 \mathrm{~mL})$ containing $50 \mathrm{~mL}$ of medium. The culture conditions to obtain the inoculum were $30^{\circ} \mathrm{C}, 150 \mathrm{rpm}, 24 \mathrm{~h}$, and $\mathrm{YM}$ medium.

\section{Batch Cultivation in Flask Culture}

Sugar cane molasses was purchased from Usina Éster (Brazil) containing 46\% of total reducing sugars (TRS) with $42.8 \%$ of sucrose and $3.2 \%$ of reducing sugars. Molasses and glycerol were sterilized separately to avoid medium darkness due to sugars reactions (caramelization and Maillard). To study different molasses and glycerol concentrations on GSH production, a central composite rotatable design (CCRD) $2^{2}$ was used with $\alpha$ equal to 1.41 , resulting in 11 trials (four axial points and three central points). Table 1 shows the coded and real levels of the variables studied with the results of biomass and GSH concentrations. The other compounds of the medium were $(\mathrm{g} / \mathrm{L})$ : corn steep liquor 50 , whey protein 50 , yeast extract 10 , magnesium sulphate 10 and lecithin $5 \mathrm{mM}$. All the chemicals and reagents used were of analytical grade. The inoculum concentration was fixed at 5\% (v/v). The fermentation process was developed in Erlenmeyer flasks $(250 \mathrm{~mL})$ containing $50 \mathrm{~mL}$ of medium at $20^{\circ} \mathrm{C}$, pH 5.0 and $300 \mathrm{rpm}$ (Santos et al. 2007) for $96 \mathrm{~h}$ with samples taken at $0,24,48,72$ and $96 \mathrm{~h}$ of incubation.

\section{Batch and Fed-Batch Cultivation in Bioreactor}

Fermentations were performed in New Brunswick Bioflo III (5 L) bioreactor. It was sterilized with the initial culture medium, except for the carbon sources, which were sterilized separately. The medium optimized in flask culture by CCRD was used in bioreactor for all the experiments. In the batch experiments, $3.5 \mathrm{~L}$ of medium was used. In fed-batch experiments, the flow rate was determined according to the working volume of the bioreactor. The initial working volume was 1.5 $\mathrm{L}$ and carbon sources were fed at constant flow $(30.6 \mathrm{~mL} / \mathrm{h})$ up to $3.5 \mathrm{~L}$ at the end of the cultivation $(96 \mathrm{~h})$. The feeding was started after sugar depletion according to literature ( $\mathrm{Li}$ et al. 1998; Liang et al. 2008a). Carbon sources and feeding solutions were fed into bioreactor using peristaltic pump. The initial $\mathrm{pH}$ was fixed at 5.0 for all the experiments. Antifoam agent (Dow Corning FG-10) was automatically added to the vessel to prevent foam formation.

Firstly, a batch fermentation (assay 1) using the conditions optimized by CCRD in flask cultures 
was done with $500 \mathrm{rpm}$ and $1.1 \mathrm{vvm}$, process conditions previously optimized by Santos (2008). In assay 2, the feeding was done with molasses (40 $\mathrm{g} / \mathrm{L})$ and glycerol $(30 \mathrm{~g} / \mathrm{L})$, while the assay 3 was done with double of these concentrations. Finally, batch experiments evaluated the influence of amino acids addition in different concentrations and cultivation times. For assay $4,4 \mathrm{mM}$ of cysteine, glycine and glutamic acid were added at $32 \mathrm{~h}$ (Wang et al. 2007) and for assay 5, $2 \mathrm{mM}$ of cysteine at $6 \mathrm{~h}$ and $3.35 \mathrm{mM}$ of cysteine, $18 \mathrm{mM}$ glycine and $10 \mathrm{mM}$ glutamic acid were added at $36 \mathrm{~h}$ (Wen et al. 2006). The amino acids solutions were sterilized through Millipore membranes $(0.2$ $\mu \mathrm{m})$.

\section{Analytical Methods}

The $\mathrm{pH}$ of the cultures was measured potentiometrically by a $\mathrm{pH}$ meter. The optical density of the sample (properly diluted) was measured using a spectrophotometer (at $600 \mathrm{~nm}$ ) to determine the cell concentration. The supernatants after centrifuging were used as blank to eliminate the interference caused by media colors. The optical density was positively related to the cell dry mass with an experimentally determined calibration curve.

Sucrose present in the molasses was converted into an equal mixture of glucose and fructose by acid hydrolysis. The total reducing sugars (TRS) consumption along the fermentations was measured in terms of glucose concentration by a colorimetric glucose oxidase peroxidase method. The intracellular GSH was extracted from the cells by $40 \%$ ethanol for $2 \mathrm{~h}$ at $30^{\circ} \mathrm{C}$ and the concentration was determined according to the method described by Owens and Belcher (1965) and Santos et al. (2007). The absorbance of the sample was measured at $412 \mathrm{~nm}$, and the concentration of GSH was obtained from a standard curve using commercial L-glutathione reduced (Fluka, Japan). The GSH yield (mg/L.h) was obtained from the GSH production per hour and percent of GSH (\%) related the GSH mass (g) in relation to cell $(\mathrm{g})$ for a specific fermentation. The data obtained are means of triplicate samples.

\section{Experimental Design}

A central composite rotatable design (CCRD) was used in flask culture assays to obtain the optimum levels of the carbon source conditions. The two factors investigated were molasses and glycerol concentrations (independent variable). Three replications of the center point and four axial points were performed to obtain a second-order model for prediction of GSH concentration (dependent variable). The design matrix, the variables, and their levels in coded and natural units are shown in Table 1. The following secondorder polynomial model was predicted by a multiple regression procedure. Equation 1 represents this empirical model related to the response.

$$
Y=a_{0}+\sum_{i=1}^{n} a_{i} x_{i}+\sum_{i=1}^{n-1} \sum_{j=i+1}^{n} a_{i j} x_{i} x_{j}
$$

where $Y$ is the predicted response in GSH concentration, $i$ and $j$ take value from 1 to the number of variables $(n), a_{0}$ is the intercept term, $a_{i}$ values are the linear coefficient, $a_{i j}$ values are the quadratic coefficient, and $x_{i}$ and $x_{j}$ are the level of the independent variables. For the analysis of the data at $72 \mathrm{~h}$ of incubation, the software Statistica 7.0 (Statsoft 2325, Tusla, OK) was used, and the adequacy of the model was evaluated through analysis of variance (ANOVA).

Table 1 - Matrix of the assays of the CCRD $2^{2}$ and results of biomass concentration (g/L) and GSH production $(\mathrm{mg} / \mathrm{L})$ for $72 \mathrm{~h}$ of incubation.

\begin{tabular}{cllll}
\hline Assay & Molasses $(\mathbf{g} / \mathbf{L}) *$ & Glycerol $(\mathbf{g} / \mathbf{L})^{*}$ & Biomass $\mathbf{g} / \mathbf{L})$ & GSH $(\mathbf{m g} / \mathbf{L})$ \\
\hline 1 & $-1(13.1)$ & $-1(13.1)$ & 14.9 & 66.1 \\
2 & $+1(76.9)$ & $-1(13.1)$ & 19.5 & 97.9 \\
3 & $-1(13.1)$ & $+1(76.9)$ & 25.3 & 78.6 \\
4 & $+1(76.9)$ & $+1(76.9)$ & 22.3 & 119.6 \\
5 & $-1.41(0)$ & $0(45)$ & 13.7 & 51.0 \\
6 & $+1.41(90)$ & $0(45)$ & 22.7 & 117.8 \\
7 & $0(45)$ & $-1.41(0)$ & 15.4 & 63.9 \\
8 & $0(45)$ & $+1.41(90)$ & 16.9 & 76.0 \\
9 & $0(45)$ & $0(45)$ & 20.0 & 106.1 \\
10 & $0(45)$ & $0(45)$ & 20.2 & 109.3 \\
11 & $0(45)$ & $0(45)$ & 21.1 & 108.7 \\
\hline
\end{tabular}

* real values in parenthesis 


\section{RESULTS AND DISCUSSION}

\section{Batch Cultivation in Flask Culture Using CCRD $2^{2}$}

An increase of the final $\mathrm{pH}$ was observed using agro-industrial substrates (molasses, corn steep liquor and cheese whey protein) for GSH production. This was probably related to proteolysis of the microorganism, a natural phenomenon that occurred after complete exhaustion of the substrate, especially when yeast did not utilize a different carbon source. As a consequence of the amino acids degradation, leading to the ammonia formation, this could be responsible for the $\mathrm{pH}$ increase. The final $\mathrm{pH}$ was higher than the initial $\mathrm{pH}$ in all the assays, reaching until 8.06 at the end of the cultivation. Increases in $\mathrm{pH}$ were also found in other studies using agro-industrial substrates such as molasses, corn steep liquor, yeast hydrolyzed (Valduga 2005 ) and hydrolyzed casein (Mantzouridou et al. 2002). The TRS were totally consumed within 24 $\mathrm{h}$ of incubation and the consumption of carbon present in the molasses was expressed as a function of the glucose concentration after hydrolysis. It was not possible to quantify glycerol consumption during the cultivation. The CCRD matrix and results of biomass concentration $(\mathrm{g} / \mathrm{L})$ and GSH production $(\mathrm{mg} / \mathrm{L})$ obtained at $72 \mathrm{~h}$ of incubation are shown in Table 1 . The highest biomass concentration $(25.3 \mathrm{~g} / \mathrm{L})$ was obtained in assay 3 and in assays with lower carbon sources concentrations (1, 5 and 7) resulted lowest biomass concentration. Among the 11 assays, GSH concentration ranged between 51.1 and 119.6 $\mathrm{mg} / \mathrm{L}$, showing the importance of carbon source suitable for GSH production. It was also found that at the same molasses concentration and with the variation of glycerol concentrations (assay 7 and 8), the GSH concentration showed a small variation (increased $15.9 \%$ ). In the assays with the same glycerol concentration and with variation of the molasses concentrations (assays 5 and 6), the
GSH concentration changed considerably (increasing 56.7\%), showing that GSH production was strongly influenced when molasses was used as the carbon source. In most assays, the GSH concentration decreased after $72 \mathrm{~h}$ of incubation. Since the goal of this experimental design was to obtain a model to describe the behavior of GSH concentration as a function of the parameters studied for the higher GSH production, the statistical analysis was performed at $72 \mathrm{~h}$ of cultivation.

The results for GSH concentration (Table 1) were analyzed by regression and variance (ANOVA) analysis. A second order model was fitted to evaluate the main effects of the two factors. The parameters were considered significant when the p-values less than $10 \%$ ( $\mathrm{p}<0.1)$. The ANOVA (Table 2) indicated that the model was significant and adequate to represent the actual relationship between the response and the significant variables with very small p-value (0.0021). The coefficient of determination $\left(\mathrm{R}^{2}\right)$ was 0.9192 , which indicated that only $8.08 \%$ of the overall variation was not explained by the model. The result of $F_{\text {calculated }}$ was 8.1 times higher than $F_{\text {tabulated }}$, indicating that the model (coded equation) was representative of the actual relationship among the selected reaction parameters (Eq. 2). The independent variable $x_{2}$ (glycerol concentration) in the investigated range, did not have significant effect on the response and was eliminated from the model and incorporated to the residual as well as the interaction between $x_{1}$ and $x_{2}$. Clearly, a higher molasses concentration led to higher GSH concentration. The model with the coded variables representing the statistically significant GSH concentration $(\mathrm{mg} / \mathrm{L})$ in terms of molasses and glycerol concentrations in the range studied is shown in Equation 1, where $x_{1}$ is the cane molasses concentration and $x_{2}$ the glycerol concentration.

$\mathrm{GSH}(\mathrm{mg} / \mathrm{L})=108.03+20.90 \cdot x_{1}-8 \cdot 47 \cdot x_{1}{ }^{2}-15 \cdot 70 \cdot x_{2}{ }^{2}$

Table 2 - ANOVA for the regression model for GSH production at $72 \mathrm{~h}$ of incubation.

\begin{tabular}{llllll}
\hline Source of variation & Sum of square & Degrees of freedom & Mean square & F-value & $\boldsymbol{p}$-value \\
\hline Regression & 5309.41 & 3 & 1769.80 & 25.89 & 0.0021 \\
Residual & 478.48 & 7 & 68.35 & & \\
Total & 5787.90 & 10 & & & \\
\hline
\end{tabular}

$\mathrm{R}=0.9192 ;{ }^{\mathrm{a}} \mathrm{F}_{3 ; 7 ; 0.1}=3.18$ 
Through the response surface generated by the model (Fig. 1A), concentrations of the molasses and glycerol were obtained to achieve higher GSH production. GSH concentration increased with the molasses concentration increasing; however, the same was not observed for glycerol, showing that the yeast preferentially consumed molasses as carbon source than glycerol. When the yeast was grown on fermentable substrates such as glucose, the metabolic energy essentially originated from glycolysis, whereas in the presence of a nonfermentable carbon source, such as glycerol, the

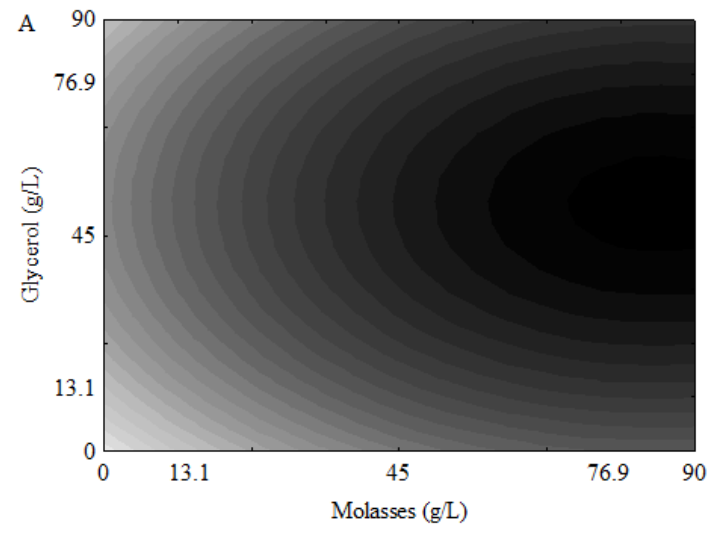

mitochondrial oxidative metabolism was fully activated (Magherini et al. 2009). This could explain the results obtained in this study. Through the response surface (Fig. 1A), it was possible to track the optimum GSH production, between 75 and $90 \mathrm{~g} / \mathrm{L}$ of molasses and between 40 to $60 \mathrm{~g} / \mathrm{L}$ of glycerol. Figure 1B presents the experimentally observed values versus the predicted values by the model (Eq. 2) for the GSH production, showing good agreement between then, as was expected by the ANOVA result.

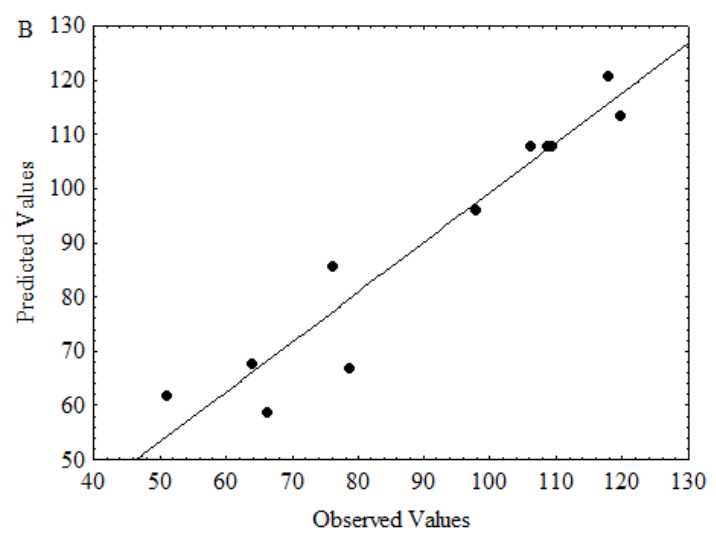

Figure 1 - Contour plot (A) and predicted values versus observed values (B) of GSH production with a CCRD $2^{2}$.

Comparing the results of biomass and GSH concentrations obtained in the flask culture by other authors using $S$. cerevisiae strains, the present study obtained very satisfactory results. The highest biomass concentration observed (25.3 $\mathrm{g} / \mathrm{L})$ was two times higher compared to other authors (Liu et al. 1999; Wen et al. 2004; Rollini and Manzoni 2006; Liang et al. 2008c). Liu et al. (1999) studied GSH production using glucose and peptone with the same Saccharomyces strain and obtained a maximum GSH concentration (124.93 $\mathrm{mg} / \mathrm{L})$ similar to the present work $(119.6 \mathrm{mg} / \mathrm{L})$. As the yeast extract and peptone are expensive, the present study applied yeast extract supplemented with whey protein and corn steep liquor. Also, molasses and glycerol were used as agro-industrial substrates instead glucose. In this way, the costs for nitrogen and carbon sources were substantially reduced. Other studies obtained lower biomass and higher GSH concentrations (Cha et al. 2004; Santos et al. 2007) than in the present study. This difference was due the stimulation on cell growth by the media used, rather the increase in the intracellular content (Wen et al. 2004), which supplied alternative amino acids and nitrogen sources that increased the GSH content with low biomass concentration.

The GSH production was also studied using glucose $(70 \mathrm{~g} / \mathrm{L})$ and molasses $(20 \mathrm{~g} / \mathrm{L})$ by $S$. cerevisiae T65 (Zhang et al. 2007) and optimized medium resulted $74.6 \mathrm{mg} / \mathrm{L} \mathrm{GSH}$. The carbon and nitrogen sources, inorganic salts, vitamins and others compounds may influence the cell growth and the accumulation of metabolic products in microbial cells. The effects of different carbon (glucose, galactose, fructose, lactose, maltose and sucrose) and nitrogen (yeast extract, peptone, tryptone, casein, soybean meal, $\left(\mathrm{NH}_{4}\right)_{2} \mathrm{SO}_{4}$, $\mathrm{NH}_{4} \mathrm{Cl}$ ) sources for GSH production were studied using S. cerevisiae FF-8 by (Cha et al. 2004). The best result $(88.4 \mathrm{mg} / \mathrm{L})$ was found when glucose and yeast extract were used. Cane molasses and glycerol proved to be viable low cost alternatives as carbon sources for GSH production. As glycerol is a byproduct of biodiesel production, it is less costly than other substrates commonly employed such as glucose. This approach could be potentially applicable to a variety of fermentative 
production processes for value-added chemicals under aerobic conditions from the viewpoints of efficiency, energy-saving, and cost-performance.

\section{Batch and Fed Batch Cultivation in Bioreactor}

The highest GSH concentration in the bioreactor was obtained at $96 \mathrm{~h}$ of batch cultivation (assay 1). Figure 2A shows the results of biomass, GSH and glucose concentration for this assay. The sugars were completely consumed at $28 \mathrm{~h}$ of cultivation. In fed-batch experiments (Fig. 2B, Fig. 2C), lower GSH and biomass concentrations were obtained. Figure $2 \mathrm{C}$ showed the results of assay 3 , which
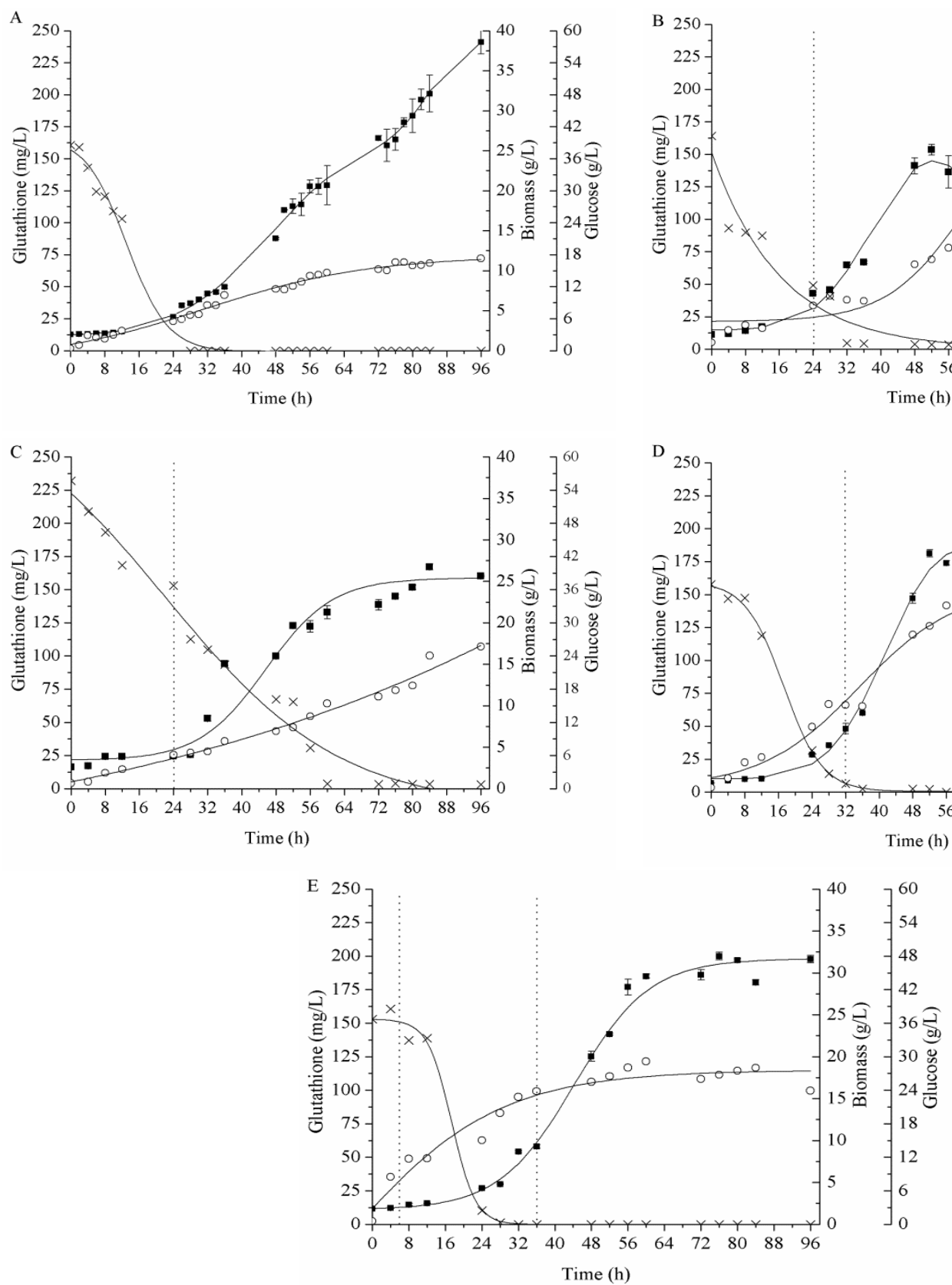

Figure 2 - Results of biomass ( $($ ), glutathione ( $)$ and glucose $(\times)$ for assays 1(A), 2(B), 3(C), 4(D), and 5(E) in bioreactor.

was used twice the concentration of molasses and glycerol in relation to assay 2 . GSH concentration reached $170 \mathrm{mg} / \mathrm{L}$, without any advantage over assay 2. Table 3 summarizes the highest responses obtained for each assay in the bioreactor. Different fed-batch strategies were studied for GSH production using C. utilis WSH $02-08$ in $7 \mathrm{~L}$ bioreactor (Liang et al. 2008b). The highest yield $(8.8 \mathrm{mg} / \mathrm{L} . \mathrm{h})$ and GSH concentration $(981 \mathrm{mg} / \mathrm{L})$ were obtained by feeding at $5.5 \mathrm{~g} / \mathrm{L}$.h after $20 \mathrm{~h}$ with biomass concentration and productivity of $102.1 \mathrm{~g} / \mathrm{L}$ and $0.84 \mathrm{~g} / \mathrm{L} . \mathrm{h}$, respectively.
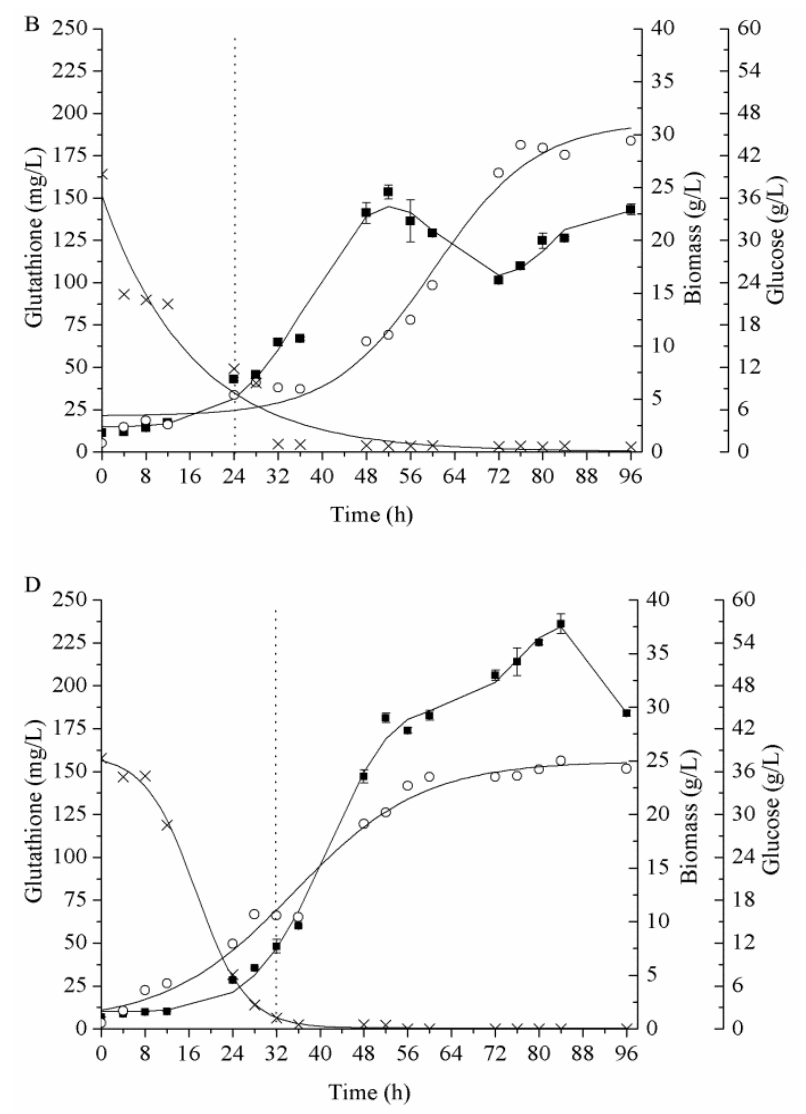
Table 3 - Maximum responses obtained in bioreactor.

\begin{tabular}{lllllll}
\hline Mode of cultivation & Assay & $\begin{array}{l}\text { Biomass conc. } \\
\text { (g/L) }\end{array}$ & $\begin{array}{l}\text { GSH conc. } \\
(\mathbf{m g} / \mathbf{L})\end{array}$ & $\begin{array}{l}\text { Biomass yield } \\
\text { (g/L.h) }\end{array}$ & $\begin{array}{l}\text { GSH yield } \\
(\mathbf{m g} / \mathbf{L} . h)\end{array}$ & GSH (\%) \\
\hline Bacth & 1 & $12.1(78 \mathrm{~h})$ & $241.3(96 \mathrm{~h})$ & $0.41(4 \mathrm{~h})$ & $2.38(96 \mathrm{~h})$ & $2.09(96 \mathrm{~h})$ \\
Fed Batch & $2^{\mathrm{a}}$ & $29.4(96 \mathrm{~h})$ & $153.6(52 \mathrm{~h})$ & $0.38(4 \mathrm{~h})$ & $2.74(52 \mathrm{~h})$ & $1.39(52 \mathrm{~h})$ \\
Fed Batch & $3^{\mathrm{b}}$ & $17.1(96 \mathrm{~h})$ & $166.9(84 \mathrm{~h})$ & $0.18(84 \mathrm{~h})$ & $2.16(36 \mathrm{~h})$ & $1.65(36 \mathrm{~h})$ \\
Amino acids addition & $4^{\mathrm{c}}$ & $25.0(84 \mathrm{~h})$ & $236.1(84 \mathrm{~h})$ & $0.40(56 \mathrm{~h})$ & $3.35(52 \mathrm{~h})$ & $0.94(84 \mathrm{~h})$ \\
Amino acids addition & $5^{\text {d }}$ & $19.4(66 \mathrm{~h})$ & $200.1(76 \mathrm{~h})$ & $1.32(4 \mathrm{~h})$ & $2.95(56 \mathrm{~h})$ & $1.24(96 \mathrm{~h})$ \\
\hline
\end{tabular}

${ }^{\mathrm{a}}$ feeding medium with molasses $(40 \mathrm{~g} / \mathrm{L})$ and glycerol $(30 \mathrm{~g} / \mathrm{L}) ;{ }^{b}$ feeding medium with molasses $(80 \mathrm{~g} / \mathrm{L})$ and glycerol $(60 \mathrm{~g} / \mathrm{L}) ;{ }^{\mathrm{c}}$ addition of $4 \mathrm{mM}$ of cysteine, glycine and glutamic acid at $32 \mathrm{~h} ;{ }^{\mathrm{d}}$ addition of $2 \mathrm{mM}$ of cysteine at $6 \mathrm{~h}$ and $3.35 \mathrm{mM}$ of cysteine, $18 \mathrm{mM}$ glycine and $10 \mathrm{mM}$ glutamic acid at $36 \mathrm{~h}$.

Even after sugar depletion, biomass and GSH still increased in the bioreactors experiments. This could have occurred because glycerol was not analyzed along the fermentations and might have been consumed as carbon source after the depletion of molasses. S. cerevisiae grew very well on glycerol as the main carbon and energy source (Penninckx et al. 1983). The growth on glycerol results in the induction of the GSH-dependent glyoxalase pathway: methylglyoxal + GSH $\leftrightarrow$ hemithioacetal (nonenzymic) hemithioacetal $\rightarrow$ SD-lactoylglutathione (glyoxalase I: EC 4.4.1.5) SD-Lactoylglutathione $+\mathrm{H}_{2} \mathrm{O} \rightarrow$ D-lactic acid + GSH (glyoxalase II: EC 3.1.2.6). The glyoxalase detoxification pathway is possibly not restricted to glycerol catabolism, but may intervene in the detoxification of other oxoaldehydes generated during yeast metabolism, for example, during catabolism of threonine, valine, and isoleucine (Murata et al. 1986).

Molasses consists of water, sucrose, proteins, vitamins, amino acids, organic acids and heavy metals such as iron, zinc, copper, manganese, magnesium, calcium, etc. Heavy metals, when contained in high concentrations in the medium, cause critical problems during the fermentation. They inhibit the microbial growth, influence the $\mathrm{pH}$ of the substrate, beside to be involved in the inactivation of the enzymes associated with biosynthesis of the product (Roukas 1998). In the aerobic GSH fermentation process, the growth of S. cerevisiae is inhibited by the excess of glucose because of a activity, which is known as the Crabtree effect (Vanurk et al. 1990). This strain (Crabtree-positive) produces ethanol when glucose concentration is not carefully controlled, decreasing the target compound's productivity. The effect of glucose addition by different feeding strategies were compared in the GSH production by Escherichia coli and was found that exponential feeding strategy increased biomass density, productivity and biomass yield ( $\mathrm{Li}$ et al. 1998). Using this strategy, biomass density and total GSH quantity in broth reached $80 \mathrm{~g} / \mathrm{L}$ and $880 \mathrm{mg} / \mathrm{L}$, respectively and inhibition of the growth was observed when the initial glucose concentration was above $20 \mathrm{~g} / \mathrm{L}$.

The increase of biomass and GSH after the sugar depletion in this study could also be related to the Crabtree effect, by which the respiratory enzymes were inhibited and ethanol was formed when the substrate concentration was above a critical value. In Sakato's report (Sakato and Tanaka 1992), it was shown that the simultaneous utilization of sugar and ethanol has been a key factors in the industrial process to produce GSH and no further increase in GSH was observed after ethanol was consumed in the medium. According to Wen et al. (2006), ethanol concentration in the medium had a significant effect on GSH content in the fed-batch culture. Low ethanol concentration was beneficial for GSH accumulation in the yeast, while high concentration exhibited inhibition on GSH production. GSH content in the fed-batch culture at low ethanol concentration was 2.3 times higher than that obtained with high ethanol concentration. The most important issues affecting the fed-batch fermentation according to Lin et al. (2004) include ethanol accumulation and dissolved oxygen concentration in the fermentation broth. Relative low value of specific growth rate $(\mu$ below $\left.0.13 \mathrm{~h}^{-1}\right)$, rich nutrition supply and high dissolved oxygen (DO) value are beneficial to avoid ethanol accumulation, to reach high biomass density and to synthesize intracellular GSH. When the setting value of $\mu$ is high (around $0.15 \mathrm{~h}^{-1}$ ), both glucose and ethanol are accumulated in the fermentation broth, which turn the metabolic pathway from aerobic cell growth to anaerobic ethanol fermentation. The concentration of glucose in the 
cultivation broth should be controlled precisely at constant low level to reduce ethanol formation and improve the yield of biomass and GSH during the fermentation. To improve GSH in the fed-batch processes it is suggested to keep the specific growth rate at low values, DO at high rates and monitoring the ethanol accumulation in the medium.

Amino acids were added in different concentrations and times of incubation. The higher GSH concentration $(236.1 \mathrm{mg} / \mathrm{L})$ was obtained with the addition of the three amino acids $(4 \mathrm{mM}$ cysteine, glycine and glutamic acid) at $32 \mathrm{~h}$ in assay 4 (Fig 2D), whereas in the experiment where amino acids were added at $6,24,48$ and $60 \mathrm{~h}$, the maximum GSH obtained was $179.45 \mathrm{mg} / \mathrm{L}$ (data not shown). These results indicated that the addition time and concentration of each of the three amino acids were key aspects in GSH increasing and should be further studied to obtain better results. The results of assay 5 are shown in Figure $2 \mathrm{E}(2 \mathrm{mM}$ of cysteine at $6 \mathrm{~h}$ and $3.35 \mathrm{mM}$ of cysteine, $18 \mathrm{mM}$ glycine and $10 \mathrm{mM}$ glutamic acid at $36 \mathrm{~h}$ ). Higher concentration of GSH was achieved during the stationary growth phase in accordance with other authors (Izawa et al. 1995; Suzuki et al. 1999). The results obtained in this study were lower than those observed by other authors. Wen et al. (2004) studied the addition of the three amino acids $(2 \mathrm{mM}$ of cysteine at $6 \mathrm{~h}$ and $10 \mathrm{mM}$ glutamic acid, glycine and serine at $35 \mathrm{~h}$ ) in fed-batch culture using S. cerevisiae T65. GSH yield was about 2.67 times higher as without amino acids. Cysteine was the most important amino acids, which increased the intracellular GSH content greatly but inhibited the cell growth at the same time. Due to the high cost and less effect of cysteine, glutamic acid and glycine were used in this study.

In other study, cysteine $(2 \mathrm{mM})$ was added at $6 \mathrm{~h}$ and $10 \mathrm{mM}$ glutamic acid, $3.35 \mathrm{mM}$ cysteine and $18 \mathrm{mM}$ glycine at 24,44 and $56 \mathrm{~h}$. GSG yield reached $2190 \mathrm{mg} / \mathrm{L}, 26.8 \%$ higher than that without any amino acids addition (Wen et al. 2006). One of the best results on GSH production with $S$. cerevisiae was reported controlling the glucose feeding by respiratory quotient and ethanol concentration. Optimized process for this strain with the addition of amino acids resulted in GSH concentration to $2020 \mathrm{mg} / \mathrm{L}$ (Wang et al. 2007). GHS metabolism has close relationship with amino acids metabolism, especially the three constituent amino acids. The addition of amino acids not only affects the cell growth but also affects intracellular GSH synthesis. The production of GSH could be enhanced by increasing the biomass concentration, or intracellular content of GSH in yeast (Wen et al. 2004). Optimal time for cysteine addition is the stationary phase as the cells stop propagating, and single-shot addition of cysteine is better than other addition ways in enhancing GSH production (Vanurk et al. 1990; Liang et al. 2008c). The simultaneous use of sugar and ethanol was shown as a key aspect for the industrial production of GSH and that GSH concentration increased after total consumption of ethanol in the medium (Wang et al. 2007). The adoption of a good method of cysteine addition can increase the rate of GSH with fed-batch in $S$. cerevisiae. However, the addition of these amino acids can cause growth inhibition and the use of glutamic acid and glycine can reduce the inhibitory effect.

\section{CONCLUSIONS}

The results demonstrated that cane molasses and glycerol, cheap substrates widely available in Brazil, have potential for use, but the addition time and concentration of each of the three amino acids would be the key aspects to increase GSH concentration and should be better studied to obtain better results. Thus, the search and/or construction of new and efficient GSH producers as well as optimization of conditions of GSH biosynthesis would assist in its bringing to market for the improvement of quality of food, cosmetic and pharmaceutical products.

\section{ACKNOWLEDGEMENTS}

The authors would like to thank the financial support from Conselho Nacional de Desenvolvimento Científico e Tecnológico (CNPq) of Brazil.

\section{REFERENCES}

Beshay U, Moreira A. Production of alkaline protease with Teredinobacter turnirae in controlled fed-batch fermentation. Biotechnol Lett. 2005; 27: 1457-1460. 
Cha JY, Park JC, Jeon BS, Lee YC, Cho YS. Optimal fermentation conditions for enhanced glutathione production by Saccharomyces cerevisiae FF-8. $J$ Microbiol. 2004; 42: 51-55.

De Deken RH. The Crabtree effect: a regulatory system in yeast. J Gen Microbiol. 1966; 44: 149-156.

Dharmadi Y, Murarka A, Gonzalez R. Anaerobic fermentation of glycerol by Escherichia coli: A new platform for metabolic engineering. Biotechnol Bioeng. 2006; 94: 821-829.

Izawa S, Inoue Y, Kimura A. Oxidative stress response in yeast: effect of glutathione on adaptation to hydrogen peroxide stress in Saccharomyces cerevisiae. FEBS Lett. 1995; 368: 73-76.

Li Y, Chen J, Mao YY, Lun SY, Koo YM. Effect of additives and fed-batch culture strategies on the production of glutathione by recombinant Escherichia coli. Process Biochem. 1998; 33: 709714.

Li Y, Wei G, Chen J. Glutathione: a review on biotechnological production. Appl Microbiol Biotechnol. 2004; 66: 233-242.

Liang G, Du G, Chen J. Enhanced glutathione production by using low-pH stress coupled with cysteine addition in the treatment of high cell density culture of Candida utilis. Lett appl microbiol. 2008a; 46: 507-512.

Liang GB, Du GC, Chen J. A novel strategy of enhanced glutathione production in high cell density cultivation of Candida utilis - Cysteine addition combined with dissolved oxygen controlling. Enzyme Microb Technol. 2008b; 42: 284-289.

Liang GB, Liao XY, Du GC, Chen J. Optimization of amino acids addition for efficient production of glutathione in Candida utilis. Biochem Eng J. 2008c; 41: 234-240.

Lin HP, Tian J, You JF, Jin ZH, Xu ZN, Cen PL. An effective strategy for the co-production of $S$ adenosyl-L-methionine and glutathione by fed-batch fermentation. Biochem Eng J. 2004; 21: 19-25.

Liu CH, Hwang CF, Liao CC. Medium optimization for glutathione production by Saccharomyces cerevisiae. Process Biochem. 1999; 34: 17-23.

Magherini F, Carpentieri A, Amoresano A, Gamberi T, De Filippo C, Rizzetto L, et al. Different carbon sources affect lifespan and protein redox state during Saccharomyces cerevisiae chronological ageing. Cell Mol Life Sci. 2009; 66: 933-947.

Mantzouridou F, Roukas T, Kotzekidou P. Effect of the aeration rate and agitation speed on beta-carotene production and morphology of Blakeslea trispora in a stirred tank reactor: mathematical modeling. Biochem Eng J. 2002; 10: 123-135.

Maris AF, Kern AL, Picada JN, Boccardi F, Brendel M, Henriques JAP. Glutathione, but not transcription factor Yap1, is required for carbon source-dependent resistance to oxidative stress in Saccharomyces cerevisiae. Curr Genet. 2000; 37: 175-182.

Murata K, Saikusa T, Fukuda Y, Watanabe K, Inoue Y, Shimosaka M, et al. Metabolism of 2-oxoaldehydes in yeasts - Possible role of glycolytic bypath as a detoxification system in L-threonine catabolism by Saccharomyces cerevisiae. Eur J Biochem. 1986; 157: 297-301.

Navarro J, Obrador E, Carretero J, Petschen I, Avino J, Perez $\mathrm{P}$, et al. Changes in glutathione status and the antioxidant system in blood and in cancer cells associate with tumour growth in vivo. Free Radic Biol Med. 1999; 26: 410-418.

Penninckx MJ, Jaspers CJ, Legrain MJ. The glutathione dependent glyoxalase pathway in the yeast Saccharomyces cerevisiae - A vital defense line against methylglyoxal produced during glycerol catabolism. J Biol Chem. 1983; 258: 6030-6036.

Rollini M, Manzoni M. Influence of different fermentation parameters on glutathione volumetric productivity by Saccharomyces cerevisiae. Process Biochem. 2006; 41: 1501-1505.

Roukas T. Pretreatment of beet molasses to increase pullulan production. Process Biochem. 1998; 33: 805810.

Sakato K, Tanaka H. Advanced control of glutathione fermentation process. Biotechnol Bioeng. 1992; 40: 904-912.

Santos LO. Study of glutathione production by Saccharomyces cerevisiae and magnetic fields evaluation during fermentations [PhD Thesis]. Campinas: State University of Campinas; 2008.

Santos LO, Gonzales TA, Ubeda BT, Monte Alegre R. Influence of culture conditions on glutathione production by Saccharomyces cerevisiae. Appl Microbiol Biotechnol. 2007; 77: 763-769.

Silva GP, Mack M, Contiero J. Glycerol: a promising and abundant carbon source for industrial microbiology. Biotechnol Adv. 2009; 27: 30-39.

Suzuki H, Hashimoto W, Kumagai H. Glutathione metabolism in Escherichia coli. J Mol Catal BEnzym. 1999; 6: 175-184.

Valduga E. Bioproduction of volatile compounds and carotenoids by Sporidiobolus salmonicolor CBS 2636 [PhD Thesis]. Florianópolis: Federal University of Santa Catarina; 2005.

Vanurk H, Voll WSL, Scheffers WA, Vandijken JP. Transient-state analysis of metabolic fluxes in crabtree-positive and crabtree-negative yeasts. Appl Environ Microbiol. 1990; 56: 281-287. 